\title{
Design and Fluid Dynamics Features of a Low- Flow High-Head Pump with Barske-Type Impeller
}

\author{
E. G. Knyazeva ${ }^{1 *}$ \\ ${ }^{1}$ HMS Group, R\&D Directorate, 125047, Moscow, Russia
}

\begin{abstract}
The article presents the results of research devoted to the design and numerical calculation of a low-flow high-head centrifugal pump with Barske-type impeller using computer simulation methods. The main features of fluid flow hydrodynamics, as well as the influence of a number of design geometry on the energy and cavitation characteristics of the pump, are found. The focus is on the analysis of the influence of the end gap between the impeller blades and the casing, as well as the cavitation qualities of the pump. The issue of cavitation qualities of a pump with different geometry of the pump inlet area investigated. In addition, a comparison of different outlet types and the selection of the best option provided. Analysis of the importance of installing the ribs in the suction line, taking into account the vortex structure of the flow in the impeller, was carried out. In addition, the results of changes in energy characteristics when pumping a working fluid with high kinematic viscosity are given.
\end{abstract}

\section{Introduction}

The technological processes of the oil and gas processing and petrochemistry require an application of the low-flow centrifugal pumps $\left(Q=5 \ldots 25 \mathrm{~m}^{3} / \mathrm{h}\right)$. Considering the specifics of these industries, the pumps must comply with the requirements of API 610, which imposes a number of restrictions both on a pump design in general, and on its energy characteristics. The conventional low-speed closed impellers $\left(n_{\mathrm{q}}=5.5 \ldots 8.0\right)$ have relatively narrow bladeto-blade channels, which can cause some technological problems in the production of such impellers. These difficulties can be avoided by applying the semi-open impellers. In terms of creating a new line of the low-flow high-head overhang centrifugal pumps of the $2 \mathrm{NK}$ series by the JSC "HMS Group" (figure 1).

\footnotetext{
* Corresponding author: knyazeva@hms.ru
} 


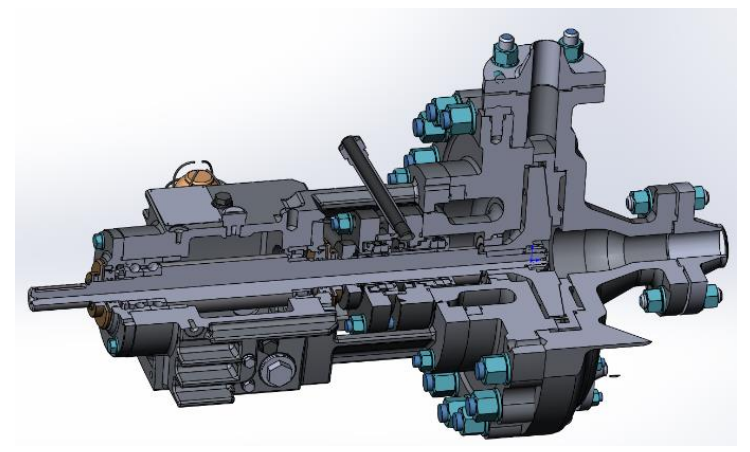

Fig. 1. 3D model of the 2NK type pump.

The research work was carried out to identify the features of hydrodynamic processes in the flow part of a pump with a semi-open impeller, which determine the energy and cavitation characteristics of such pump.

The following general requirements must be taken into account when designing the flow part:

- Head curve $H=H(Q)$ in the flow range of $Q=(0.3 \ldots 1.25) Q_{\text {rated }}\left(Q_{\text {rated }}-\right.$ rated flow) should be of low steepness (almost horizontal);

- NPSH3 in the operating range shall be less than NPSH3 $<2.0 \mathrm{~m}$;

- An easy assembly and disassembly by refinery station employees shall be ensured;

- Maximum design unification with 2NK series pumps shall be provided.

The Barske-type impellers are widely used under the low flow and high head conditions $\left(n_{q}=4 \ldots 7\right)$ (figure 2).

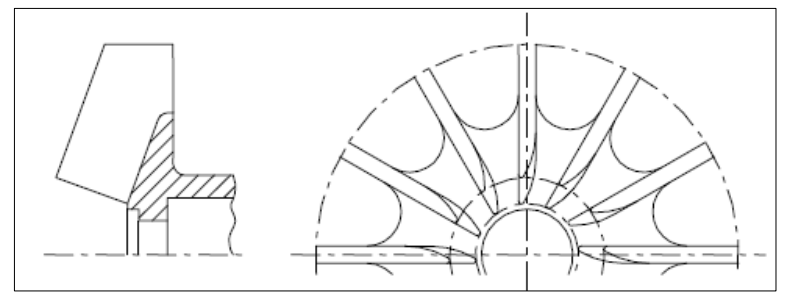

Fig. 2. Semi-open Barske-type impeller [1].

At the same time, in the USSR's practice, the semi-open Dobrokhotov-Ivanov type impellers with an efficiency of up to $\eta=40 \ldots 45 \%$ are known. The blade profile of this impeller is not strictly radial if compared with the Barske-type impeller (figure 3).

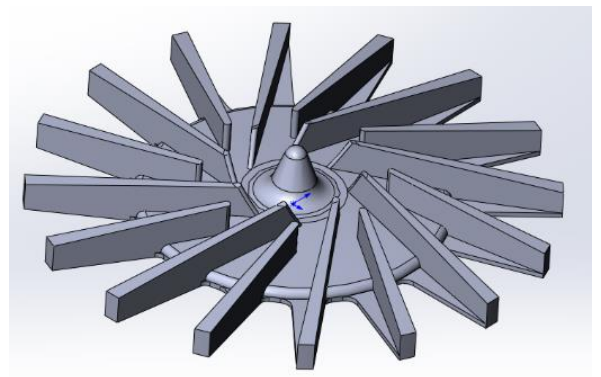

Fig. 3. Semi-open Dobrokhotov-Ivanov type impeller. 
The main feature of the hydrodynamic process occurring inside the impeller of this type is the formation of a system of radial vortices in each blade-to-blade channel due to the "opening" of an axial gap between the casing and the blade-to-blade channel on both sides (figure 4).

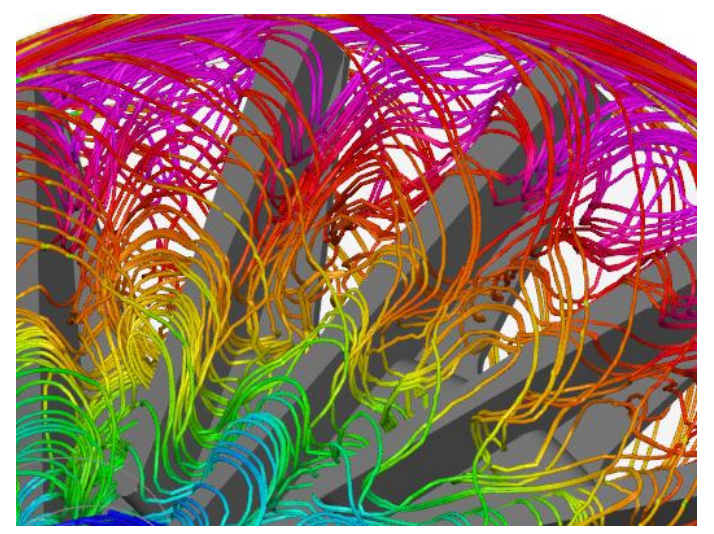

Fig. 4. Radial vortex in the inter-blade channel of the Dobrokhotov-Ivanov type impeller.

The presence of this vortex structure results in as follows:

- The head is increased by up to $40 \%$ as compared to the closed impeller.

- The head doesn't depend on the gap value (within certain limits) between the impeller blades and the casing (figure 5). The numerical experiment confirmed the independence of the head parameter from the value of an axial gap (Gap $=0.05 b_{2} \ldots 0.25 b_{2}$, where $b_{2}$ is a width of an impeller at the outlet) and maintaining a high level of efficiency (figure 6).

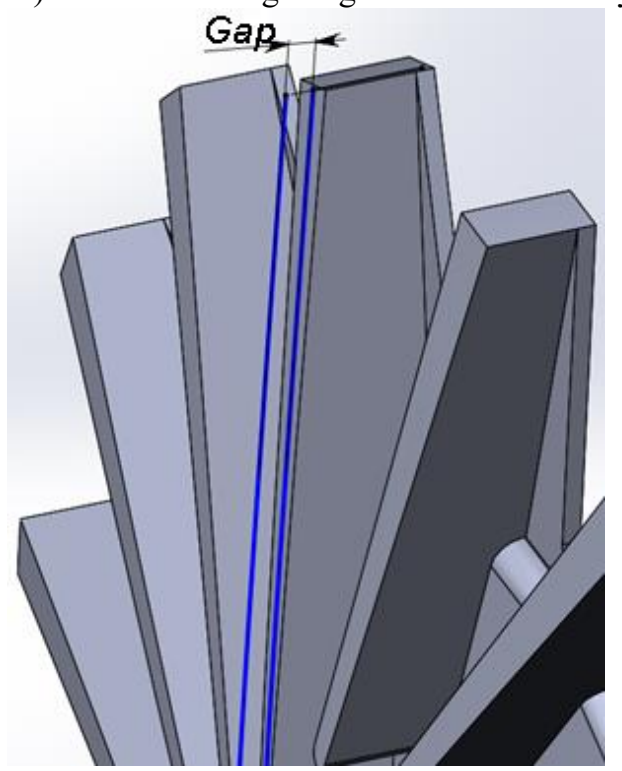

Fig. 5. Gap between the impeller blades and the discharge casing. 


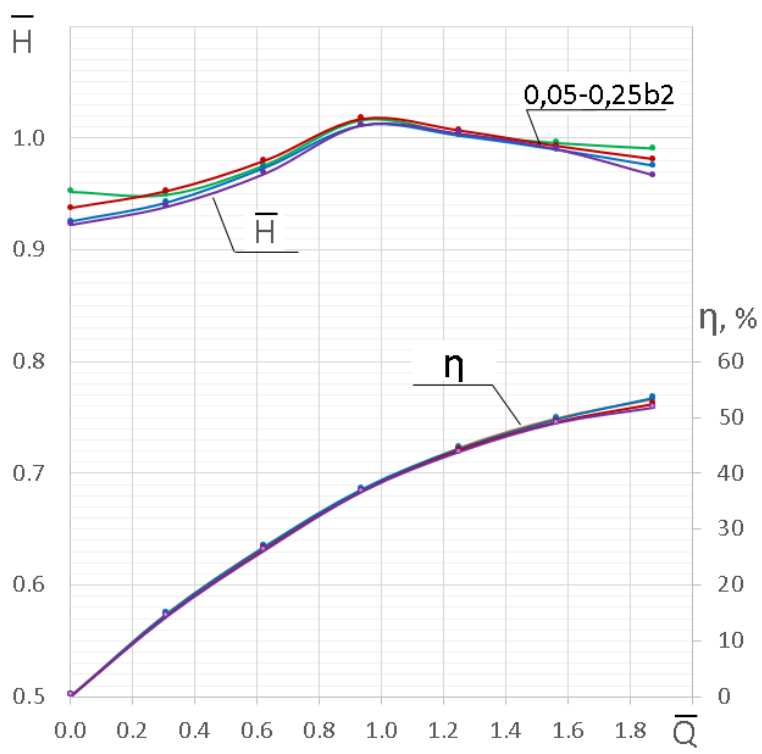

Fig. 6. The results of a numerical experiment for a pump with the Dobrokhotov-Ivanov type impeller.

Since the low-falling shape of the head curve is preferred according to the requirements of API 610, the application of an impeller with radial blade (blade angle $\beta_{2 \mathrm{~b}}=90^{\circ}$ ) $-\mathrm{a}$ Barske-type impeller [2] - is further considered.

This article presents a part of the results of the research work, the purpose of which was to use the CFD tools at the design stage to answer practical questions related to the geometry, flow hydrodynamics and future operation of the pump, including:

- Influence of the outlet casing on the energy characteristics and the overall dimensions.

- Stability and shape of the pump head curve when varying the size of the tip clearance (Gap) between the impeller blades and the casing.

- Cavitation pump characteristics.

- Influence of the fluid viscosity on the energy characteristics.

- The influence of the pump inlet elements on the flow hydrodynamics in the suction pipeline in the under-load modes.

The article presents the results of the design and numerical calculation of the 2NK 16125 pump $\left(n_{q}=4.7\right)$ with the Barske-type impeller.

\section{Research method}

The analysis of the integral energy and cavitation parameters, as well as the hydrodynamics of the flow inside the flow part of a pump, was carried out on the basis of a numerical experiment using the PumpLinx software (Simerics) [3-5]. The design model is shown in figure 7. It allows simulating the flow of liquid in the full flow part, taking into account the supply and discharge pipelines (same as on the test bed). 


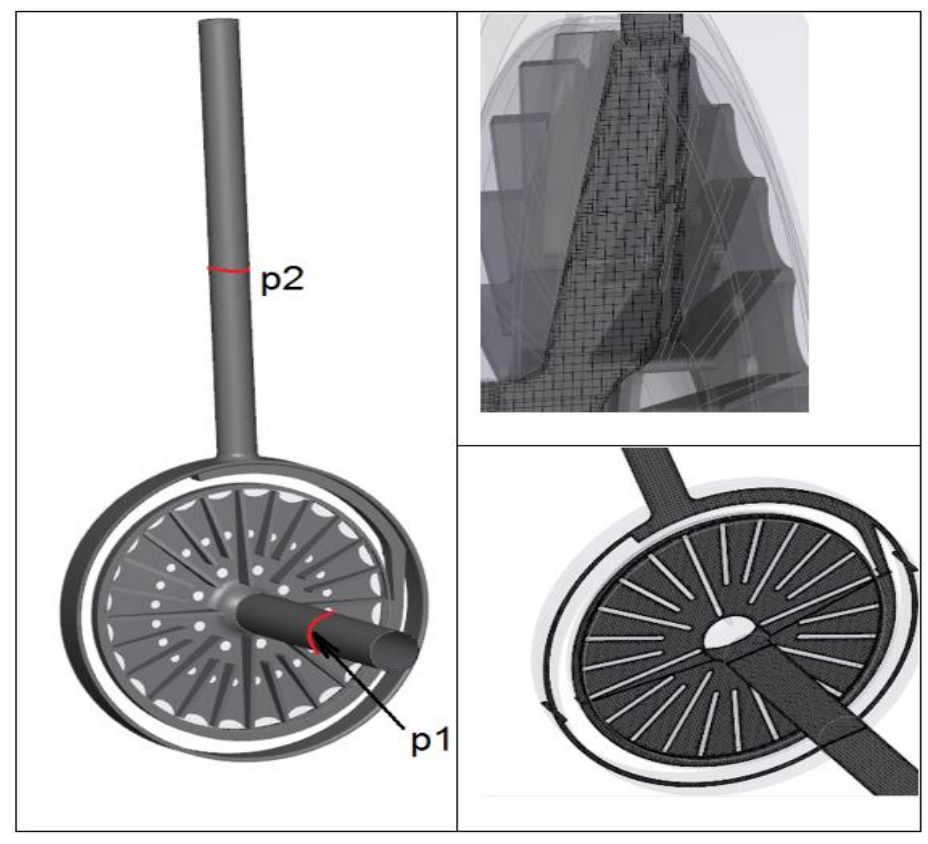

Fig. 7. The flow part model for the numerical experiment.

\section{Selecting the outlet casing}

Analysis of an outlet casing number showed that the single-channel diffuser (figure 8), which is similar to the traditional spiral volute with flow output to the axis, is preferred in terms of a combination of factors such as energy efficiency, manufacturability, weight and size characteristics, and the possibility of a replaceable rotor application. As a comparison, figure 9 (a) shows the flow patterns for three-channel diffuser, the application of which results in a $13 \%$ efficiency reduction as compared to a single-channel diffuser, as well as the 9-channel diffuser (a drop in efficiency by $18 \%$ ) - figure 9 (b).

In further calculations, single-channel diffuser was used as an outlet casing.

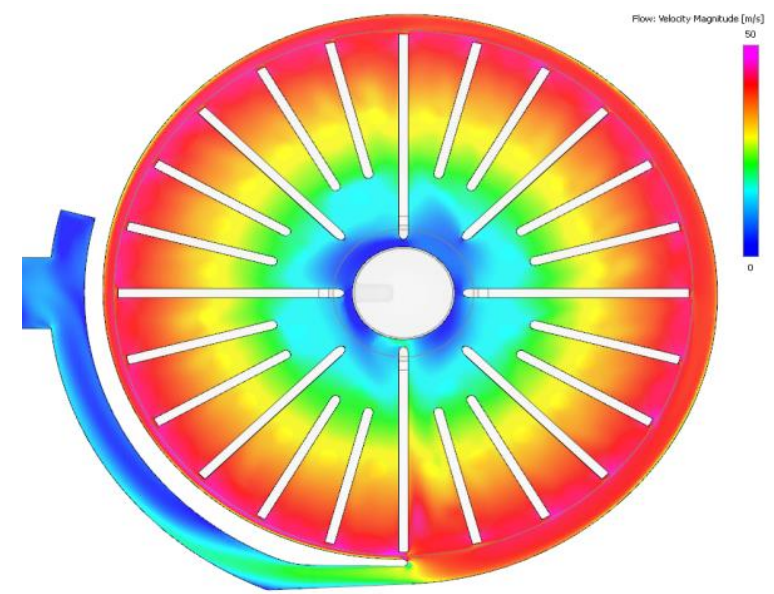

Fig. 8. The velocity field in a longitudinal section of the flow part with a single-channel diffuser. 


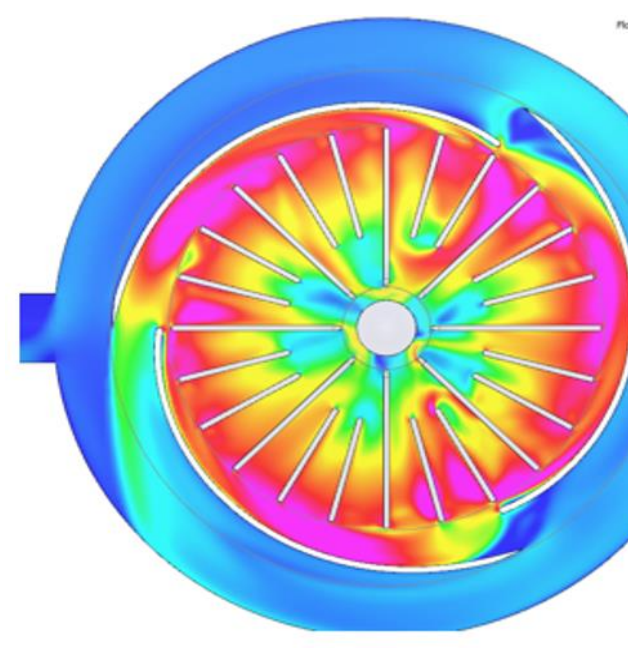

(a)

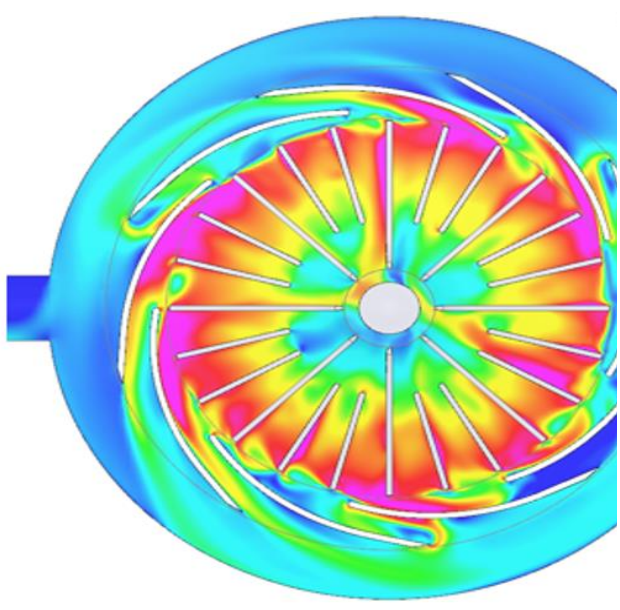

(b)

Fig. 9. The velocity field in a longitudinal section of the flow part with various options of the outlet devices: $\Delta \eta=-13 \%$ (a); $\Delta \eta=-18 \%$ (b).

\section{Correlation between the energy characteristics and the tip clearance (gap)}

One of the most important questions when considering the operation of pumps with semiopen impellers is the effect of the tip clearance (gap) between the blades and the casing on the change and stability of the head curve. This is also stated, for example, in [6].

According to the results of numerical calculations, in case of the investigated flow part (figure 8$)$ in the gap range of Gap $=(0.03 \ldots 0.25) b_{2}$, the steepness of a head curve decreases as the gap decreases (figure 10).

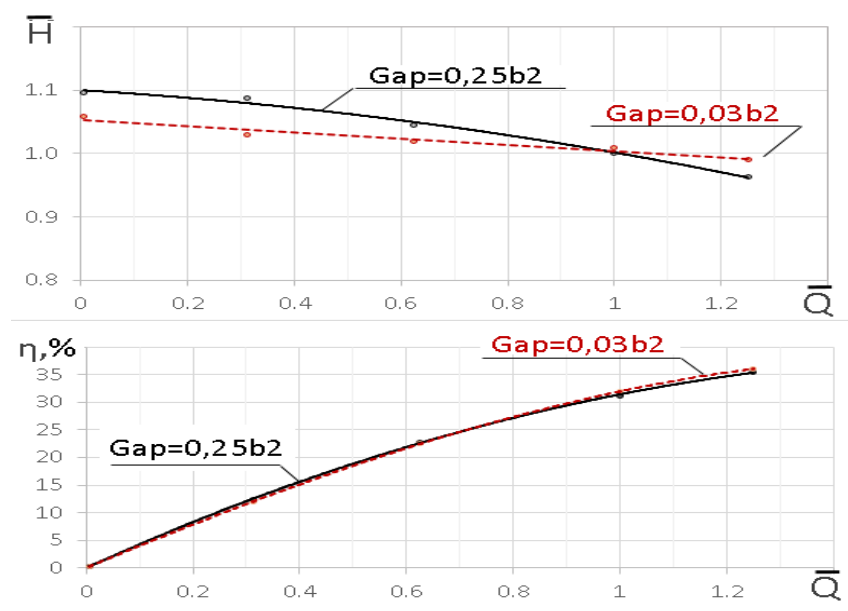

Fig. 10. Dependence of the energy characteristics on a value of the gap according to the results of a numerical experiment. 
In case of a small gap ( $\left.\mathrm{Gap}=0.03 b_{2}\right)$, the gradual relative reduction of the head with decreasing flow rate is a consequence of the fact that the smaller the gap, the smaller the attached mass of liquid, which circulates between the impeller channels and gives an additional circulation (figure 11).

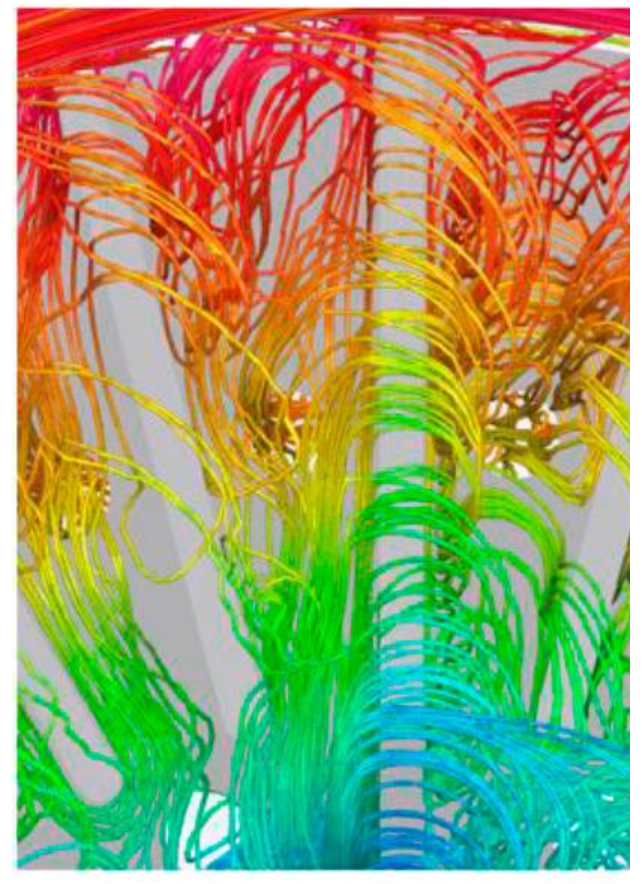

(a)

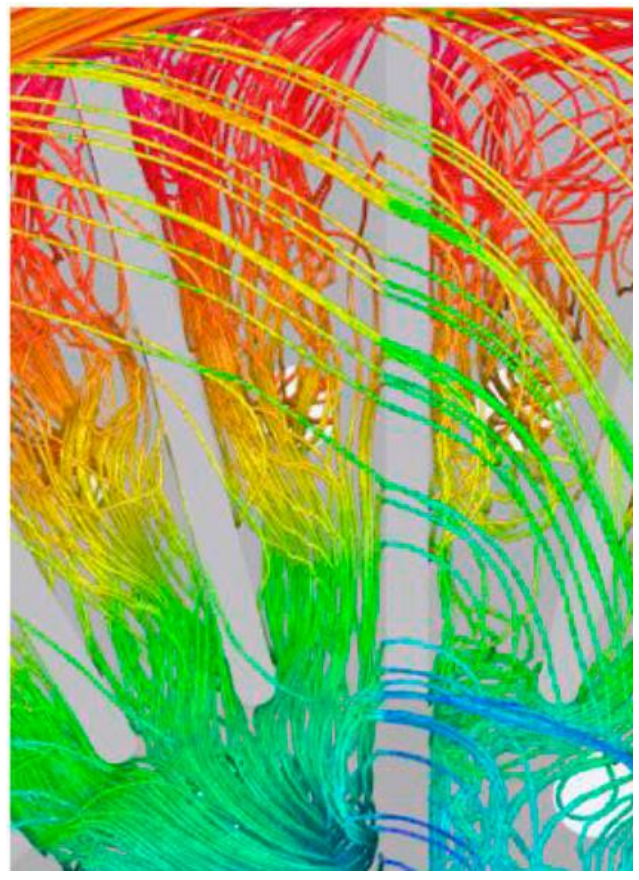

(b)

Fig. 11. Dependence Streamlines at gap with $G a p=0.25 b_{2}$ (a) and Gap $=0.03 b_{2}$ (b), mode $Q=0.006 Q_{\text {rated. }}$

These results are in full agreement with the following theoretical assumptions. It is known from the theory [7], that the theoretical pump head characteristic under the assumption of an infinite number of blades with $\beta_{2 \mathrm{~b}}=90^{\circ}$ does not depend on flow rate, that is the head characteristic is horizontal (figure 12). If the gap decreases (tending to zero), we approach the option of the closed impeller with blades that have an output angle $\beta_{2 \mathrm{~b}}=90^{\circ}$.

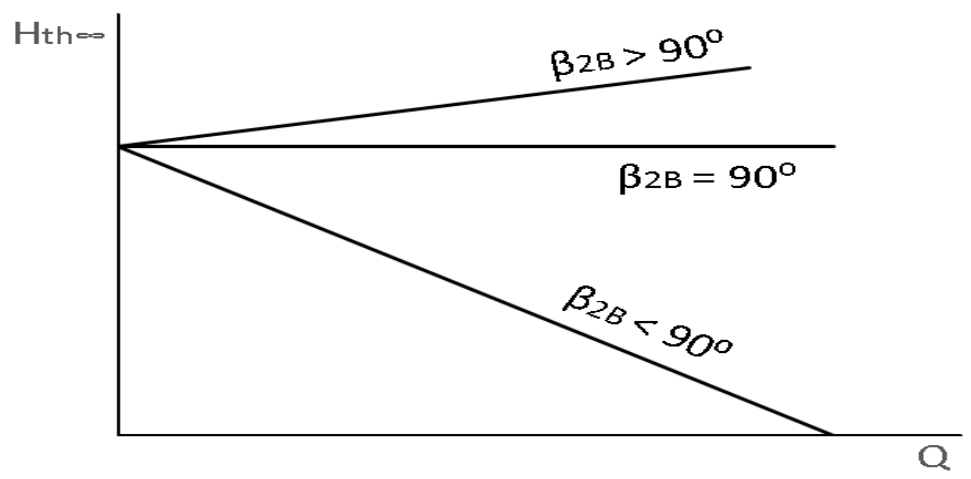

Fig. 12. Characteristics of a centrifugal pump for various blade shapes [7]. 
Consideration of the flow hydrodynamics for the flow part with Gap $=0.25 b_{2}$ in the blade-to-blade channels of the impeller at different modes of operation (figure 13) shows that the intensity of the vortex flow changes slightly. It increases slightly in the under-load modes. These results are consistent with the fact, that the head curve has a declining shape with a slight steepness. The value of the transient pulsation of gap vortex as an important factor for flow instability and stall of centrifugal impeller was established also in [8].

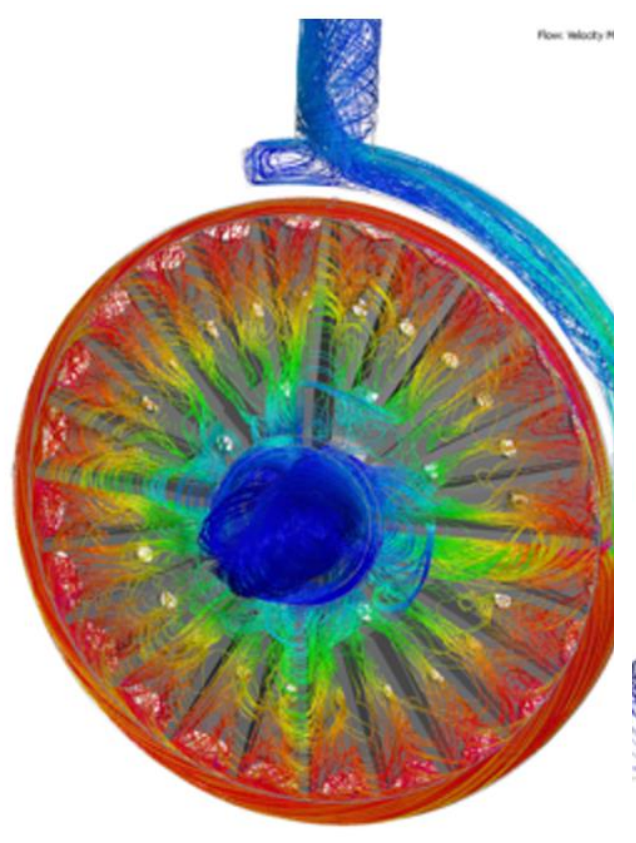

(a)

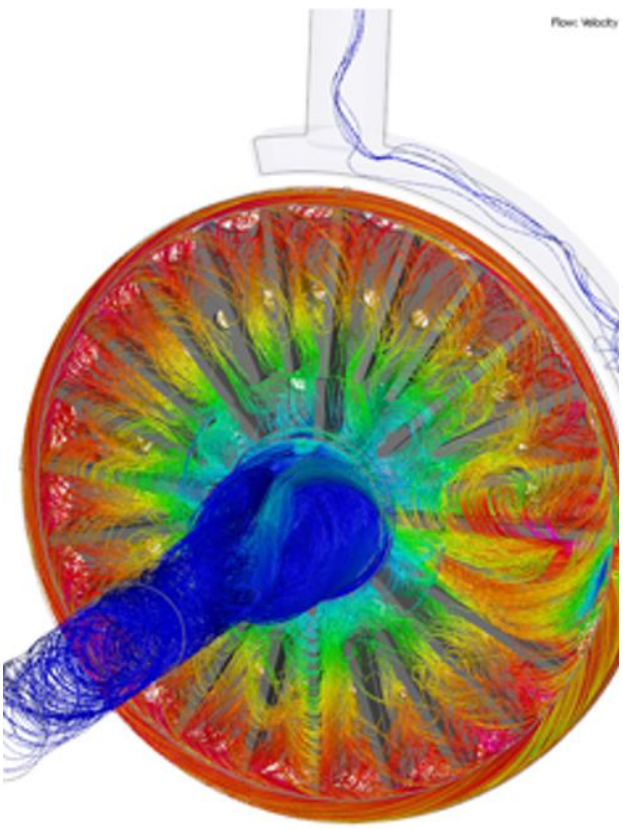

(b)

Fig. 13. The distribution of streamlines at the end gap at different modes of operation: $Q=16 \mathrm{~m}^{3} / \mathrm{h}$ (a); $Q=0.1 \mathrm{~m}^{3} / \mathrm{h}(\mathrm{b}) ; \mathrm{Gap}=0.25 b_{2}$.

Besides, it was found that it is possible to adjust the axial force $F_{\text {axial, }}$ acting on the pump rotor, by varying the number of balance holes in the hub disc. In our case, the control range was from $F_{\text {axial }}=17000 \mathrm{~N}$ (hub disc without balance holes) to $F_{\text {axial }}=350 \mathrm{~N}$ (three rows of balance holes in the hub disc). Confirmation of the balance holes value on the axial thrust was also set in [9].

\section{Cavitation research}

An analysis of the numerical experiment data showed that for a Barske-type impeller with a vortex flow in the blade-to-blade channels the same picture is observed as for classic centrifugal impellers: the wider the inlet throat area, the higher the anti-cavitation properties. This is visually demonstrated by the cavern development pattern at the $Q=1.0 Q_{\text {rated }}$ mode (table 1). At the same time, as the inlet area is extended, the energy performance loss is not observed, whereas such loss usually occurs when the throat of a classical centrifugal impeller is extended significantly. The cavern development pattern shows that caverns begin to appear in the impeller inlet area at a cavitation velocity coefficient of $n_{\mathrm{ss}}=64$, which can be explained by a 90 -degree flow direction change and a sharp local increase in the velocity and, consequently, a decrease in static pressure in this area. 
The effect of a pre-installed inducer on the change in cavitation properties is also an issue of interest. Several inducer options with a different blade solidity and location in front of the impeller were considered. A common conclusion for all considered options is that the installation of the inducer leads to the fact that the structure of the flow at the impeller blades entrance becomes worse, the local speed increases and, therefore, the appearance and development of cavities becomes earlier in comparison with the options without a inducer. Fig. 15 shows a comparison of the caverns development patterns for the options with and

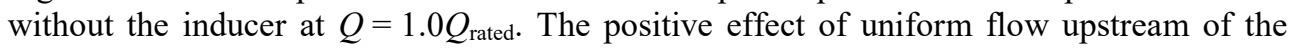
impeller inlet on improving the cavitation performance was found in [10].

Table 1. The development of the caverns for the different options at $Q=1.0 Q_{\text {rated. }}$

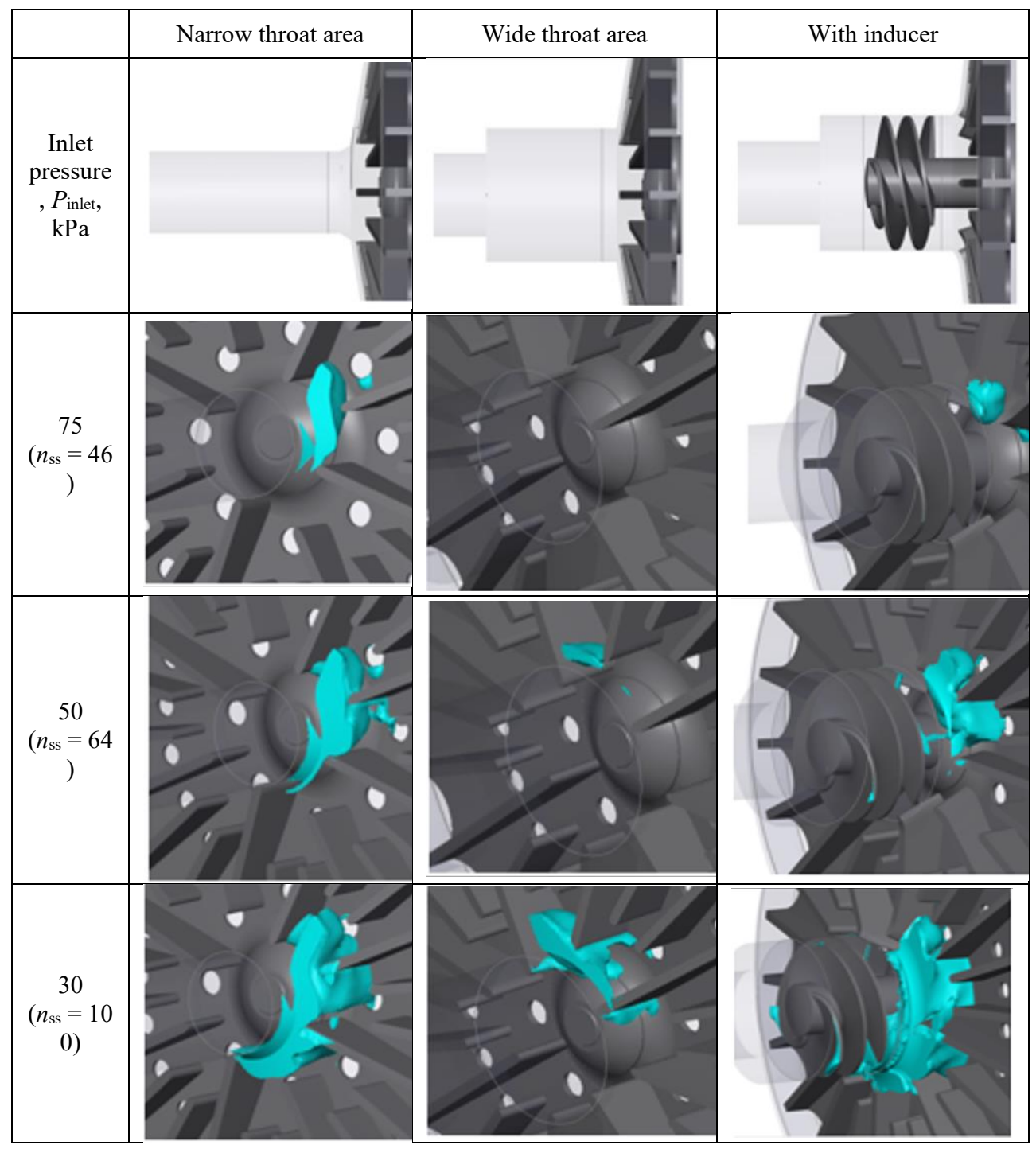




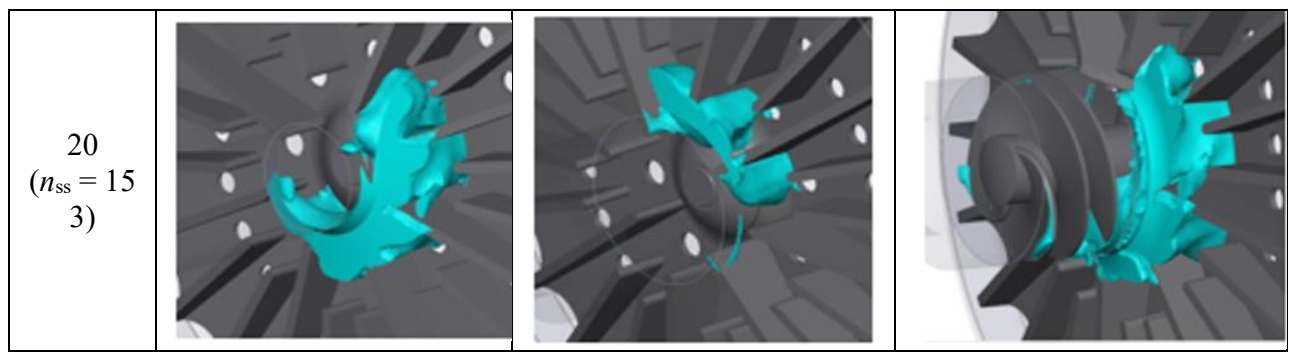

As a result, the NPSH3 curve for the flow range $Q=(0.3 \ldots 1.25) Q_{\text {rated }}$ was obtained (figure14) for pump option with an extended cylindrical inlet area and without inducer. As it can be seen from the chart, the $\mathrm{NPSH} 3=\operatorname{NPSH} 3(\bar{Q})$ parameter does not exceed $\mathrm{NPSH} 3=1.2 \mathrm{~m}$, which satisfies the initial design requirements for this pump (NPSH3 $<2.0 \mathrm{~m})$.

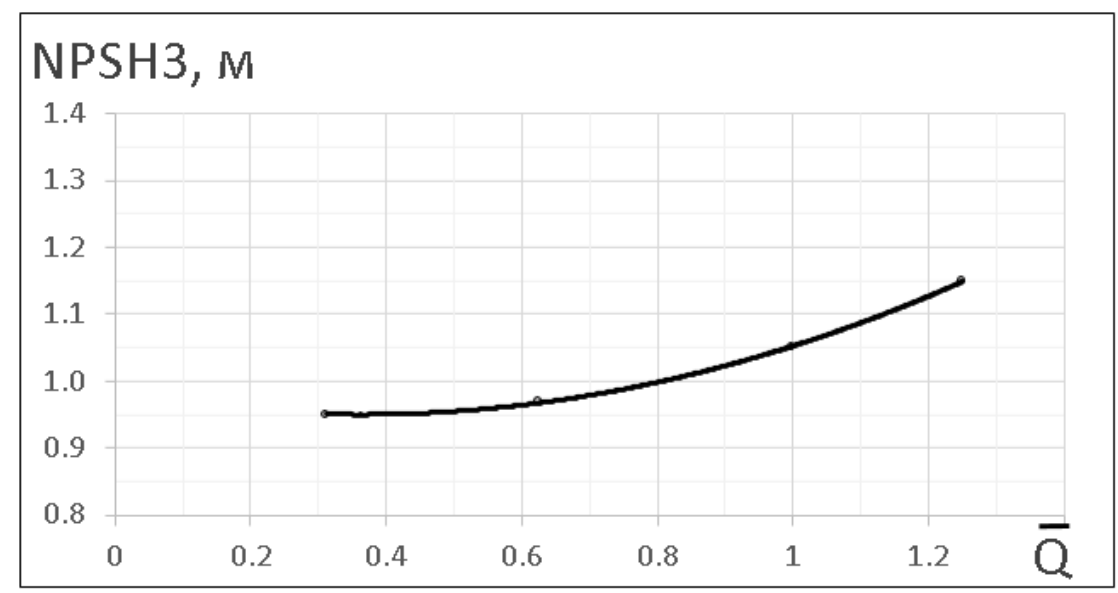

Fig. 14. NPSH3 curve of the 2NK16-125 pump without an inducer.

\section{Inlet rib}

One of the requirements for this type of pump is a steady operation in a wide flow range: $Q=(0.3 \ldots 1.25) Q_{\text {rated. }}$ From this point of view, an important issue is the reliability of the connected pipelines operation, including the permissible noise and vibration level in the suction pipeline, associated with development of the reverse vortices at the impeller inlet in the under-load flow modes and further spread of this vortex into a suction line. In addition, in contrast to the conventional closed centrifugal impeller [11], the impeller with radial blades has a vortex motion in the blade-to-blade channels in all operating modes. In this regard, the effect of installing the inlet rib in front of the impeller was considered.

Table 2 represent a visual comparison of the numerical calculation results for two options - with and without a rib. When comparing a flow in the suction pipe in the rated mode $Q=Q_{\text {rated }}$ (table 1), it can be noted that the installation of a rib makes the flow structure before the impeller more uniform, although even in the case of no rib the vortex does not go into the suction line. A different picture is observed in the under-load mode $Q=0.3 Q_{\text {rated }}$ (table 1): in the absence of a rib, a more intensive twisted vortex structure, formed at the impeller inlet area, spreads to the suction pipe area at a much greater distance. 
Table 2. Flow structure in the suction pipe at different operating modes.

\begin{tabular}{|c|c|c|}
\hline & $Q=1.0 Q_{\text {rated }}$ & $\mathrm{Q}=0.3 Q_{\text {rated }}$ \\
\hline $\begin{array}{l}\text { With } \\
\text { inlet } \\
\text { rib }\end{array}$ & Sin & \\
\hline $\begin{array}{l}\text { Witho } \\
\text { ut } \\
\text { inlet } \\
\text { rib }\end{array}$ & 5 & \\
\hline
\end{tabular}

In terms of influence on energy parameters, it was found that an inlet rib barely affects the head curve in this case (figure 15).

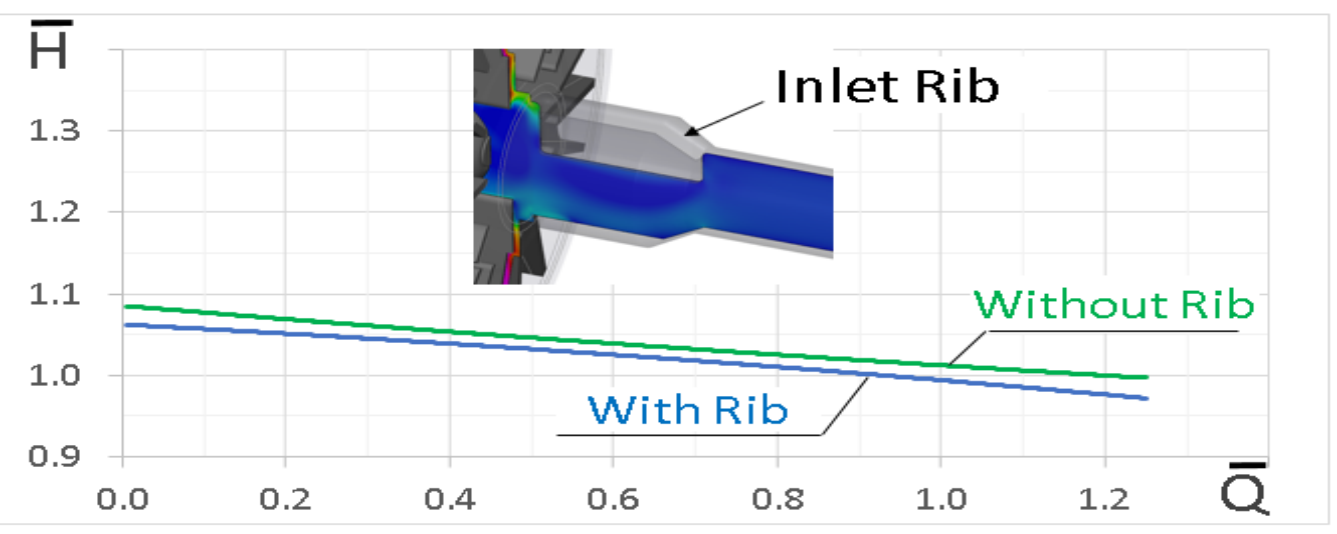

Fig. 15. Influence of an inlet rib on the head curve.

Thus, one can conclude that the installation of a rib is essential for the pumps with Barsketype impellers.

\section{The influence of a viscosity on the energy characteristics}

Since the 2NKseries pumps are used in the refinery and petrochemical processes, the kinematic viscosity of operating fluid may differ. Therefore, an issue of changing the head and efficiency high viscosity is of practical interest [12]. As an example, figure 16 shows a dimensionless compare of the head and efficiency curves for two viscosities, which shows that when the kinematic viscosity is increased to $v=85 \mathrm{cSt}$, the head decreases by $30 \%$, while the efficiency decreases by $17 \%$. 


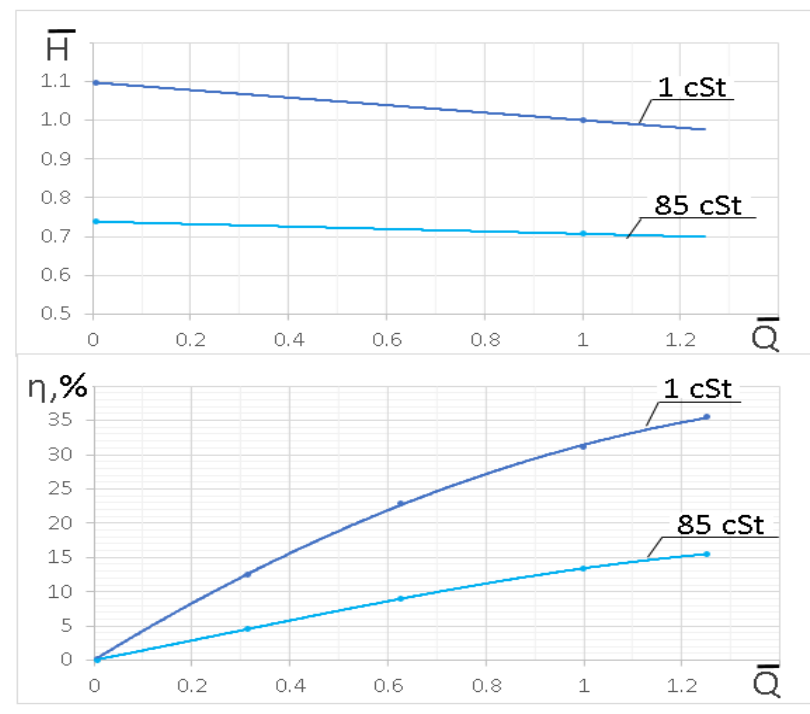

Fig. 16. The comparative results of a numerical simulation of the flow with different kinematic viscosity.

In terms of hydrodynamics, as the viscosity increases, the intensity of circulation in the gap decreases, the liquid flows along the casing in this area "without going" into the impeller channels (figure 17).

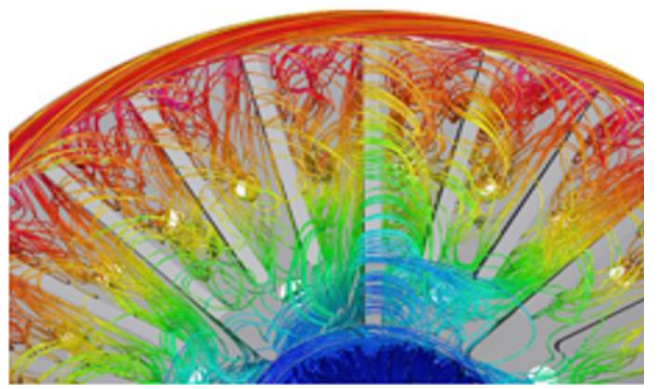

(a)

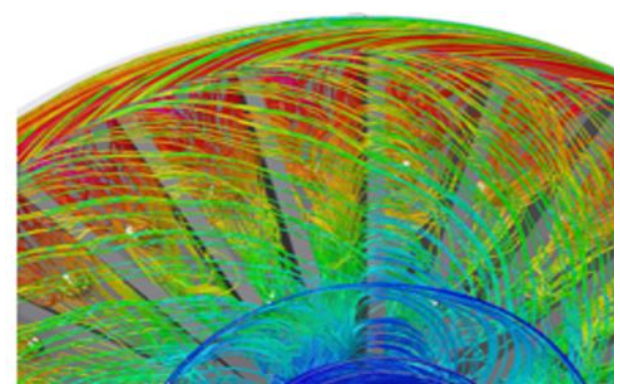

(b)

Fig. 17. The flow in the impeller channels and gap at the kinematic viscosity of $v=1 \mathrm{cSt}$ (a) and $\nu=85 \mathrm{cSt}(\mathrm{b})$ at $Q=1.0 Q_{\text {rated. }}$

\section{Conclusion}

- The basic hydrodynamic features of a low-flow high-head pump with a Barske-type impeller were revealed on the example of the 2NK 16-125 $\left(n_{\mathrm{s}}=17\right)$ pump by means of the numerical simulation tools.

- The most preferable type of an outlet casing was determined in terms of energy efficiency, as well as the requirements for manufacturability and the possibility to use the interchangeable rotors.

- Analysis of the flow hydrodynamics in the flow part showed the possibility of regulating the degree of steepness of the head curve $H=H(Q)$ by changing the tip clearance (gap) 
between the impeller blades and the casing while maintaining the pump efficiency at the level of $\eta=31.5 \%$.

- A number of numerical calculations for different pump inlet configurations, including configuration with a pre-installed inducer, revealed the possibility of ensuring the NPSH3 of less than $2.0 \mathrm{~m}$ throughout the entire working flow rate range without application of an inducer.

- The correlation between changes in energy parameters and the liquid kinematic viscosity was determined.

\section{References}

1. J. F. Gülich, Centrifugal pumps (Villeneuve, Switzerland: Springer International Publishing), 2020

2. Low Flow Options, Pupms and systems magazine, pp.20-24, September (1994)

3. J. Li and Chen X. L. The Flow Simulation of A Fuel Centrifugal Pump with Integrated Inducer and Impeller Influenced by Inlet Flow Ejector Proceedings of 2018 9th International Conference on Mechanical and Aerospace Engineering, ICMAE 2018 (Institute of Electrical and Electronics Engineers Inc.) pp 561-564, 2018

4. H. Ding, Visser F. C., Jiang Y. and Furmanczyk M. Demonstration and validation of a 3D CFD simulation tool predicting pump performance and cavitation for industrial applications Journal of Fluids Engineering, Transactions of the ASME 133, 2011

5. P. Li, Huang Y. F., Li J., Li P., Huang Y. F. and Li J. Cavitation simulation and NPSH prediction of a double suction centrifugal pump IOP Conference Series: Earth and Environmental Science vol 15 (IOP Publishing) p 062025, 2012

6. A. F. Ayad, Abdalla H. M. and El-Azm Aly A. A. Effect of semi-open impeller side clearance on the centrifugal pump performance using CFD Aerospace Science and Technology 47 247-55, 2015

7. V. S. Lobanoff and Ross R. R. Centrifugal Pumps: Design and Application (Elsevier Inc.), 1992

8. J. L. Lu, L. Guo, L. K. Wang, Wang W., Guo P. C. and Luo X. Q. Research on the Unsteady Flow of Tip Clearance in Semi-open Impeller Centrifugal Pump. Trans. Chin. Soc. Agric. Mach. 50 163-172, 2019

9. Z. Lisheng, J. Jin, Zhihuai X. and Yanhui L. Numerical Investigation of the Effect of Balancing-Hole on the Axial Force of a Partial Emission Pump (ASME International), 2014

10. X. Luo, Liu S., Zhang Y. and Xu H. Cavitation in semi-open centrifugal impellers for a miniature pump Frontiers of Energy and Power Engineering in China 2 31-5, 2008

11. K. Luo, Wang Y., Liu H., Chen J., Li Y. and Yan J. Effect of suction chamber baffles on pressure fluctuations in a low specific speed centrifugal pump Journal of Vibroengineering 21 1441-55, 2019

12. R. Torabi and Nourbakhsh S. A. The effect of viscosity on performance of a low specific speed centrifugal pump International Journal of Rotating Machinery, 2016 